\title{
Surgical Outcome of Hundred Vesico Vaginal Fistula Patients in National Fistula Centre
}

\author{
*Akhter $\mathrm{S}^{1}$, Mahbuba $\mathrm{M}^{2}$, Yusuf $\mathrm{NA}^{3}$, Munirunnessa ${ }^{4}$, Rosy $\mathrm{N}^{5}$
}

\begin{abstract}
:
Vesico-vaginal fistula (VVF) is still a major global health problem. This study was performed to detect the surgical outcome of 100 VVF patients in National Fistula Centre. A descriptive cross sectional study was carried out among 100 VVF patients fulfilling the inclusion criteria admitted in the National Fistula Centre under the department of Obstetrics and Gynaecology during the study period of April, 2017 to September, 2017. During the period, 100 patients presented for surgical repair at a mean age of 28.7 years (SD7.1). Majority of them (49\%) had a parity of one and $57 \%$ were less than 20 years old at the time of their first pregnancy. About 83\% of women developed VVF following prolonged obstructed labour. Most of the fistula (95\%) repaired through vaginal route by flap splitting technique and $73 \%$ repaired at $1^{\text {st }}$ time. Recovery of most of the patient (75\%) was uneventful. Inadequate post-operative care (26.9\%) was the major causes of unsuccessful repair. Obstetric fistula is one of the tragedies of third world countries and it would be better solved by providing surgical procedure and easy access of all women to competent obstetrical care, irrespective of their social and economic status during pregnancy and delivery.
\end{abstract}

Keyword: Vesico-vaginal fistula (VVF), Surgery, Outcome

\section{INTRODUCTION}

Urogenital fistula represents a major global health problem, responsible for significant physical, social and

1. *Dr. Shamima Akhter, Assistant Professor. Department of Obstetrics \& Gynaecology, Mugda Medical College \& Hospital, Dhaka. Phone: 01715-051020

2. Dr. Mst. Mahbuba, Medical Officer, Dhaka Medical College \& Hospital, Dhaka

3. Dr. Nusrat Ara Yusuf, Junior Consultant, Mugda Medical College \& Hospital, Dhaka

4. Dr. Munirunnessa, Assistant Professor, Department of Obstetrics \& Gynaecology, Sir Salimullah Medical College, Dhaka

5. Dr. Nasrin Rosy, Assistant Professor Department of Obstetrics \& Gynaecology, Sir Salimullah Medical College, Dhaka

*For correspondence psychological morbidity. ${ }^{1}$ Vesico-vaginal fistula is the most common type. A vesico-vaginal fistula (VVF) is an abnormal fistulous tract between the bladder and vagina, causing continuous dribbling of urine via the vagina. ${ }^{2}$ Vesico-vaginal fistula results mainly from obstetrical and gynaecological causes. It is mostly caused by child birth in developing countries like Bangladesh when a woman with prolonged obstructed labour is delivered by unskilled birth attendant, no emergency obstetric care (EOC), lack of proper obstetric management, adolescent pregnancy and repeated child birth. ${ }^{1}$ It can also be associated with complicated hysterectomy, following cancer operation, radiation therapy and during cone biopsy. ${ }^{3}$ Radiation treatment for pelvic cancer can lead to fistula formation as reported in $1.4 \%$ to $5.2 \%$ of post-radiation hysterectomies. ${ }^{2}$ Focal injuries to the genitourinary tract during hysterectomy and caesarean section causes VVF. Additional causes of vesico-vaginal fistula are congenital abnormalities, infection, trauma and foreign bodies but these are relatively rare. ${ }^{1}$

The exact magnitude of VVF worldwide is unknown. The world health organization (WHO) estimates that the prevalence of obstetric fistula is $0.3 \%$ of all deliveries. ${ }^{1,4}$ However the WHO estimated that over 20 million women are living with this condition with 50,000 to 100,000 new cases per annum. ${ }^{5}$ This is attributed to poverty, illiteracy, ignorance and poor obstetric services. In low resourced countries (LRC), VVF most often results following neglected prolonged obstructed labour. In contrast, urogenital fistula are relatively uncommon in well resourced countries (WRC). In LRC, while between 30,000 and 1,30,000 new fistulas developed annually ${ }^{6}$. In Bangladesh, UNFPA (United Nation Population Fund) and Engender Health report finds that the number of women living with fistula is estimated to be 1.69 per 1000 ever married women. ${ }^{7}$ According to this report women living with fistula in Bangladesh are usually in the age group of 15-30 years, illiterate, poor and unaware that treatment is available, or cannot access or afford it .To date, very few concerted efforts have been undertaken to address 
the fistula issue. ${ }^{5}$ In Bangladesh 8,00,000 to $10,00,000$ women are estimated to be awaiting repair. ${ }^{7}$

The outcome of VVF repair depends on many factors like site, size, number of fistula, bladder capacity and amount of scarring etc. Other associated responsible factor includes good preoperative assessment and care, timing of operation, effective post operative care and lastly expertise of the surgeon. ${ }^{7}$

\section{MATERIALS AND METHOD}

This descriptive cross sectional study was carried out in the National Fistula Centre, Department of Obstetrics and Gynaecology of Dhaka Medical College and Hospital, Dhaka, during the period of April 2017 to September 2017.The criteria for inclusion were diagnosed as a case of VVF and patient willing to participate in the study. Detailed medical and obstetric history was taken and thorough examination was done and all the informationwere recorded in the pre-designed data collection sheet. The information recorded on the sheet was based on detailed history taking by interviewing the patients and attendants, proper clinical examination (sometimes examination under anesthesia), type and location of fistula, methods and attempts of repair that included socio-demographic data,post operative complications and results of operations. All the information and data were systematically recorded and were analyzed by SPSS version 23 and was shown in the tabulated form. The quantitative data were expressed in frequency and mean+/-SD and the qualitative data were expressed in frequency and percentage.This study was approved by the Ethical committee of the Dhaka medical college.

\section{RESULTS}

Table I is showing that, 100 patients presented for surgical repair at a mean age of 28.7 years (SD7.1). Forty-nine had a parity of one, and 57 were less than 20 years old at the time of their first pregnancy. Thirty-nine experienced incontinence for one to five years at the time of presentation, with 15 women suffering incontinence for longer than five years.

Table II shows that based on complexity of fistula, more than half $(53 \%)$ were simple (up to $3 \mathrm{~cm}$ ). Depending on the location of the fistula, $48 \%$ were at juxta-cervical region and $25 \%$ were mid vaginal. Sub-symphysial fistula was $15 \%$ and juxta-urethral was $12 \%$.
Table I: Socio-demographic characteristics of the VVF patients

\begin{tabular}{|c|c|}
\hline Patient characteristic & Frequency $(\mathrm{n}=100)$ \\
\hline \multicolumn{2}{|c|}{ Age at presentation (years) } \\
\hline $11-15$ & 12 \\
\hline $16-20$ & 4 \\
\hline $21-25$ & 55 \\
\hline $26-30$ & 7 \\
\hline $31-35$ & 5 \\
\hline $36-40$ & 7 \\
\hline $41-45$ & 3 \\
\hline$>45$ & 7 \\
\hline mean $(\mathrm{SD})$ & $28.7(7.2)$ \\
\hline \multicolumn{2}{|l|}{ Education: } \\
\hline no education & 56 \\
\hline Primary & 23 \\
\hline Secondary & 12 \\
\hline Higher Secondary & 9 \\
\hline \multicolumn{2}{|l|}{ Marital status: } \\
\hline Married & 48 \\
\hline Divorcee & 32 \\
\hline Separated & 18 \\
\hline Widow & 2 \\
\hline \multicolumn{2}{|l|}{ Parity: } \\
\hline 1 & 49 \\
\hline $2-5$ & 35 \\
\hline$>5$ & 16 \\
\hline Mode & 1 \\
\hline \multicolumn{2}{|c|}{ Age at first pregnancy (years) } \\
\hline $10-19$ & 57 \\
\hline $20-29$ & 35 \\
\hline $30-39$ & 8 \\
\hline Mean (SD) & $19.5(3.1)$ \\
\hline \multicolumn{2}{|c|}{ Duration of incontinence } \\
\hline$<3$ months & 17 \\
\hline 3 months-1 year & 29 \\
\hline $1-5$ year & 39 \\
\hline$>5$ year & 15 \\
\hline Mean (SD) & 2.6(4.1) years \\
\hline
\end{tabular}


Table II: Types of fistula

\begin{tabular}{|l|c|c|}
\hline Types & Frequency & Percentage \\
\hline Based on complexity: & & \\
\hline Simple up to 3 cm & 53 & $53 \%$ \\
\hline Complicated $>3 \mathrm{~cm}$ & 47 & $47 \%$ \\
\hline Depending on the site of fistula & & \\
\hline Juxta-cervical (vault fistula) & 48 & $48 \%$ \\
\hline Mid Vaginal & 25 & $25 \%$ \\
\hline Juxta urethral & 12 & $12 \%$ \\
\hline Subsymphysial & 15 & $15 \%$ \\
\hline
\end{tabular}

Table III: causes of fistula

\begin{tabular}{|l|c|}
\hline Causes of fistula & Frequency \\
\hline Obstructed labour & 83 \\
\hline Instrumental delivery & 10 \\
\hline Caesarean section & 3 \\
\hline Hysterectomy & 2 \\
\hline Trauma & 1 \\
\hline Others & 2 \\
\hline
\end{tabular}

Table III is showing the causes of VVF in the 100 patients. Among these commonest causes of fistula is obstructed labour (83\%).

Table IV: Routes of repair of VVF

\begin{tabular}{|l|c|c|}
\hline Routes of repair & Frequency & Percentage \\
\hline Trans-vaginal & 95 & 95 \\
\hline Flap splitting method & 9 o & \\
\hline Saucerization & 1 & \\
Colpocleisis & 2 & \\
\hline Repair by graft & 2 & \\
\hline Trans-abdominal & 4 & 4 \\
\hline Trans-vesicle & 4 & \\
\hline Trans-peritoneal & 0 & \\
\hline Combined-abdominal-vaginal & 1 & 1 \\
\hline
\end{tabular}

Table IV is showing that most of the fistulas were repaired through vaginal route by flap splitting technique and only $4 \%$ were repaired abdominally (Trans-vesicle approach).
Table V: Distribution of patients according to attempts of repair $(n=100)$

\begin{tabular}{|l|c|c|}
\hline Number of attempts & No. of patients & Percentage \\
\hline 1st & 74 & 74 \\
\hline 2nd & 21 & 21 \\
\hline 3rd & 3 & 3 \\
\hline 4th & 2 & 2 \\
\hline Total & 100 & 100 \\
\hline
\end{tabular}

Table V shows that, out of 100 patients, $74 \%$ were repaired at $1^{\text {st }}$ time, $21 \%$ were repaired at $2^{\text {nd }}$ attempt and $3 \%$ were at $3^{\text {rd }}$ attempt. Only $2 \%$ repaired at $4^{\text {th }}$ attempt.

Table VI: Functional outcome among the successfully repaired patients of VVF ( $n=73)$

\begin{tabular}{|l|c|c|}
\hline Functional outcome & Frequency & Percentage \\
\hline No dribbling & 66 & 90.41 \\
\hline Stress incontinence & 7 & 9.59 \\
\hline Mild & 5 & \\
\hline Severe & 2 & \\
\hline Total & 73 & $100 \%$ \\
\hline
\end{tabular}

Table- VI showing that, out of 73 successfully repaired patient, $90.54 \%$ was really dry, rest $9.46 \%$ had mild to severe incontinence.

Table- VII: post-operative complications

\begin{tabular}{|l|c|}
\hline Complications & Number of patients \\
\hline Blocked catheter & 5 \\
\hline Catheter leakage & 7 \\
\hline Hemorrhage & 2 \\
\hline UTI & 5 \\
\hline Pyrexia & 4 \\
\hline Wound infection & 2 \\
\hline None & 75 \\
\hline Total & 100 \\
\hline
\end{tabular}

Table- VII shows recovery of most of the patients (75\%) were uneventful, catheter leakage( $7 \%)$, blocked catheter $(5 \%)$, hemorrhage( $2 \%)$, UTI $(5 \%)$, pyrexia( $(4 \%)$, wound infection $(2 \%)$ were the leading complications.

Table- VIII: Outcome of repair

\begin{tabular}{|l|c|c|}
\hline Outcome & No. of patients & Percentage \\
\hline Successful & 73 & $73 \%$ \\
\hline Unsuccessful & 27 & $27 \%$ \\
\hline Total & $100 \%$ & $100 \%$ \\
\hline
\end{tabular}


Table- VIII: Causes of unsuccessful repair

\begin{tabular}{|l|c|c|}
\hline Causes of unsuccessful repair & No. of patients -26 & Percentage \\
\hline Drop out & 13 & $50 \%$ \\
\hline After 1ST attempt & 3 & $11.53 \%$ \\
\hline Afteranother attempt & 10 & $38.46 \%$ \\
\hline Inadequate post-operative care & 7 & $26.9 \%$ \\
\hline Operative Failure & 6 & $23.07 \%$ \\
\hline Total & 26 & $100 \%$ \\
\hline
\end{tabular}

Table- VIII, among the 100 patients, seventy three cases of VVF was repaired successfully. The rate of unsuccessful operation was $27 \%$.

Table- VIII is showing the causes of unsuccessful VVF repairs. Out of 26 unsuccessful repair drops out were 50\%. Inadequate post-operative care was in $26.9 \%$ and operative failure was in $23.07 \%$ of the cases.

\section{Table IX: Duration of hospital stay}

\begin{tabular}{|c|c|}
\hline Duration & Frequency \\
\hline$<1$ month & 68 \\
\hline$>1$ month & 32 \\
\hline
\end{tabular}

Table IX is showing that $68 \%$ patients stayed less than 1 month in the Hospital.

\section{DISCUSSION}

In this descriptive cross-sectional study, $100 \mathrm{VVF}$ cases were included. Out of the 100 patients presented for surgical repair at a mean age of 28.7 years. In the present study $49 \%$ of VVF patients had a parity of one, and $57 \%$ were less than $20 \%$ years old at the time of their first pregnancy. 39\% experienced incontinence for one to five years at the time of presentation, with $15 \%$ suffering from incontinence for longer than five years. This findings are almost similar to a study carried out at Kumudini Women's Medical College Hospital in 2011 by Begum $^{2}$.Based on the complexity of fistula, there was no such huge difference between the prevalence of simple (up to $>3 \mathrm{~cm})$ and complicated $(<3 \mathrm{~cm})$ fistula which was $53 \%$ and $47 \%$ respectively. These findings are quite similar with a study done by Humaira in DMCH in $2003^{9}$. Prevalence of complicated fistulas were found quite similar to simple fistula in $\mathrm{DMCH}$ may be due to $\mathrm{DMCH}$ is the highest referral center for VVF patients. Most of the difficult complicated and large sized fistulas are referred to $\mathrm{DMCH}$. Based on the location, $48 \%$ were at Juxtra-cervical region which is more than the previous studies done atKumudiniWomens Medical college Hospital in 2011 and $\mathrm{DMCH}$ in $2003 .{ }^{9}$ Eighty three percent women with VVF had the features of obstructed labour. This findings are inconsistent with that of done by Humaira ${ }^{9}$ and Begum. $^{2}$ About $66.6 \%$ of the cases of VVF were found due to obstructed labour in a study done in 2013 by Mazher. ${ }^{8}$ Many international studies have also labeled obstetrical trauma to be the major cause of VVF in under developed countries. 5,6,7 Most of the fistulas (95\%) were repaired through vaginal route by flap splitting Technique. This findings are similar to the previous findings in $\mathrm{DMCH} .{ }^{9}$ Predominance of vaginal route was found also in other countries. ${ }^{10}$ Out of 74 successfully repaired patients, $66 \%$ were really dry, no dribbling of urine detected. This is also in accordance with other studies carried out in our country. ${ }^{2}$ Recovery of most of the patients $(75 \%)$ were uneventful ${ }^{9}$. The rate of unsuccessful operation is 26 among 100 patients. Drop outrate was 50\%. Inadequate post-operative care was one of the major causes of unsuccessful repair (26.9\%). Present finding varies from another study carried out at $\mathrm{DMCH}$ done by Humaira where post operative mismanagement were found in $33 \% .{ }^{9}$

\section{CONCLUSIONS}

This study clearly analyzed the outcome of repair of vesico-vaginal fistula. Most of the cases had successful repair in $\mathrm{DMCH}$. The study population was selected from one selected hospital in Dhaka city, so that the result of the study may not represent the whole population. More training and skill of surgeons for repair of fistulas, employing modified techniques wherever applicable can improve the result. Post-operative mismanagement and catheter problem can be minimized to get maximum successful outcome of repair Obstructed labour is the 
major causes of VVF in the study which indicates the poor antenatal and intranatal care in Bangladesh. Though concerted action, in our country, we can prevent fistula though proper treatment, who are still suffering from fistula. Increase awareness about VVF and knowledge how to prevent it and treatment providing in tertiary level hospital through government and non government organization should be encouraged.

\section{REFERENCES}

1. Hillary C, Osman N, Hilton P, Chapple C. Treatment, and Outcome of Urogenital Fistulae Managed in Well and Low-resourced countries: A Systemic Review. European Urology. 2016; 70(30): 478-92.

2. Begum B, Khandakar S, Rahman F. A study on Outcome of VVF Repair at KumudiniWomens Medical College hospital. Bangladesh Med J. 2014; 40(3):8-9

3. Das S, Begum R, Chowdhury B. Obstetric Fistula and Common Peroneal Nerve palsy in rural Based Women: A case Report. ChattagramMaa O-Shishu Hospital medical College Hospital. Journal. 2015; 14(1):2-3
4. EzegweiHNwogu-Ikojo E. Vesico-Vaginal fistula in Eastern Nigeria. Journal of Obstetrics and Gynaecology. 2005; 25(6):589-591.

5. Yousuf F, Tahir M, Sheikh S. Vesico-Vaginal fistula (VVF)- A prospective analysis. Annals KEMU.2016; 109(2):15

6. Pal A, Ray K, Bhadra D, Lahiri K. Surgical repair of genital fistulae analysis of 62 cases in a tertiary hospital. The Journal of Obstetrics and Gynaecology of India. 2010;60(5):424-24

7. Romics I, KelimanZ,Fazakas Z. Diagnosis and management of Vesico Vaginal fistulae. BJU International. 2002; 89(7): 764-66.

8. Mazhar S, Riaz G,Akhter S, Out Come of VesicoVaginal fistula Repair.Pakistan Journal of Medical And Health Sciences. 2013;7(3):843-845

9. Homaira R, Khatun S, Zabin F. A study on Different Surgical Methods used for Repair of Vesico-Vaginal fistulas in Dhaka Medical College Hospital. Medical Today. 2010; 22(1):12-14.

10. Kelly J. Vesico-Vaginal fistula and recto-Vaginal fistula. Journal of the Royal society of medicine. 1992; 85(5):257-58. 